\title{
Grain Boundary Diffusion of Nickel in $\gamma$-Iron*
}

\author{
By Yuko Hanatate**, Kazuhiko Majima***, and Hiroyasu Mitani***
}

\begin{abstract}
In order to understand the role of $\mathrm{Ni}$ in enhancing the sintering of $\mathrm{Fe}-\mathrm{Ni}$ powder compacts, the grain boundary diffusion coefficient of ${ }^{63} \mathrm{Ni}$ in $\gamma-\mathrm{Fe}$ is determined in the temperature range from 1153 to $1287^{\circ} \mathrm{C}$ by the residual-activity counting method using the instantaneous source model proposed by Suzuoka.
\end{abstract}

The results are expressed as follows:

Volume diffusion: $D=1.09 \times 10^{-4} \cdot \exp \left(-296.7 \mathrm{~kJ} \cdot \mathrm{mol}^{-1} / R T\right) \mathrm{m}^{2} / \mathrm{s}$

Grain boundary diffusion: $D^{\prime}=24.1 \times 10^{-4} \cdot \exp \left(-176.2 \mathrm{~kJ} \cdot \mathrm{mol}^{-1} / R T\right) \mathrm{m}^{2} / \mathrm{s}$.

(Received June 8, 1978)

\section{Introduction}

It is well known that nickel enhances sintering of ferrous powder compacts ${ }^{(1)}$. The present authors have confirmed that the presence of nickel in the grain boundaries is the cause of the enhancement ${ }^{(2)}$. In order to understand the mechanism, the reliable boundary diffusion data of nickel into iron is desired. Up to the present there are two reports ${ }^{(3)(4)}$ on the diffusion of nickel into iron, although there is a marked disagreement between the two. Both are based on the assumption ${ }^{(5)}$ that the concentration of the nickel source at the surface of the medium does not change during the diffusion period.

In this experiment, the authors determined the boundary diffusion coefficients of nickel into $\gamma$-iron at a relatively high temperature range from 1153 to $1283^{\circ} \mathrm{C}$ taking into account the change in the concentration of the surface source with time during diffusion ${ }^{(6)}$.

\section{Experimental Procedure}

Irion sepcimens used in this experiment were cylindrical, $5 \mathrm{~mm}$ in length and $11 \mathrm{~mm}$ in diameter. Electrolytic iron with the chemical

* This paper was originally published in Japanese in J. Japan Inst. Metals, 41 (1977), 1211.

** Graduate School, Osaka University, Suita. Present address: Osaka Prefectural Industrial Research Institute, Osaka 550, Japan.

*** Department of Materials Science, Faculty of Engineering, Osaka University, Suita 565, Japan.

Trans. JIM
Table 1 Chemical composition of Fe specimen (\%).

\begin{tabular}{cccccc}
\hline \hline $\mathrm{C}$ & $\mathrm{Mn}$ & $\mathrm{Si}$ & $\mathrm{P}$ & $\mathrm{S}$ & $\mathrm{Cu}$ \\
0.0035 & 0.0050 & 0.0041 & 0.0011 & 0.0062 & 0.0015 \\
\hline $\mathrm{Ni}$ & $\mathrm{Cr}$ & $\mathrm{Al}$ & $\mathrm{O}$ & $\mathrm{N}$ & $\mathrm{Fe}$ \\
0.0013 & 0.0017 & 0.0120 & 0.0036 & 0.0020 & rest \\
\hline
\end{tabular}

composition listed in Table 1 was used. The ${ }^{63} \mathrm{Ni}$ isotope, which decays with the emission of $0.063 \mathrm{MeV} \beta$ particles and has a half life of 93 years, was obtained in the form of an acid chloride solution. The layer of the isotope about $0.1 \mu \mathrm{m}$ in thickness was electroplated onto the flat faces of the specimens from a sôlution of nickel sulfate, nickel chloride, ammonium chloride and boracic acid containing both radioactive and inert nickel ions.

The specimens plated with ${ }^{63} \mathrm{Ni}$ by the abovementioned procudure were sealed in quartz amples under a vacuum of $1.3332 \times 10^{-3} \mathrm{~Pa}$ and diffusion-annealed in furnaces controlled within $\pm 1^{\circ} \mathrm{C}$. After the diffusion anneal, the sample diameters were decreased about $1 \mathrm{~mm}$ on a precission lath, and the diffusion coefficient was determined by the residual-activity technique, where the activity measurements for the $\beta$-radiation of ${ }^{63} \mathrm{Ni}$ were made on the disc specimens of $10 \mathrm{~mm}$ diameter, by using of a low-background counter ${ }^{(7)(8)}$, after removal of successive layers of $5-10 \mu \mathrm{m}$ from the surface.

\section{Experimental Results}

The penetration curves of ${ }^{63} \mathrm{Ni}$ into the iron specimens diffusion annealed at various tem-

$$
1978 \text { Vol. } 19
$$




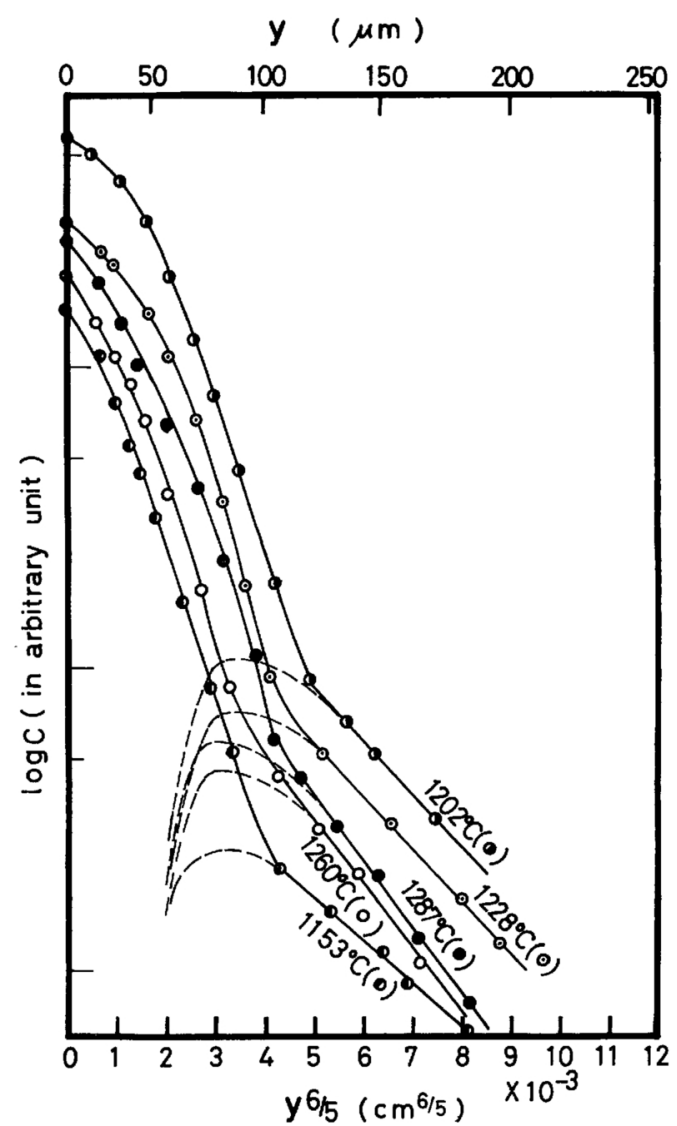

Fig. 1 Penetration curves of $\mathrm{Ni}$ in $\mathrm{Fe}$.

peratures are shown in Fig. 1, where the logarithm of the concentration is plotted against the $6 / 5$ power of the penetration depth. In every case, one will see that the curve consists of the part due to the lattice diffusion from the surface and the linear part due to the grain boundary diffusion in the region away from the surface more than $100 \mu \mathrm{m}^{(9)}$, and the slope- $\gamma$ of the linear part is found to be in the following relation:

$0.973 \log (\Delta-1)=6.567-1.644 \log \gamma-\log \sqrt{D t}$,

where $\Delta$ is $D^{\prime} / D$. According to eq. (1), it is obvious that $D^{\prime}$ is easily obtained where $D$ is known. However, the literature values of $D$ are at variance with each other. Therefore, in this experiment, the self-consistent method $^{(6)(9)}$ which allowed a simultaneous determination of $D$ and $D^{\prime}$ was used.
The observed values are analysed by the relation:

$$
C_{\mathrm{obs}}=K\left(C_{1}+1 / n N_{2}\right),
$$

where $K$ is constant, $n=b / \sqrt{D \cdot t}$, and $2 b$ is the mean linear grain size. Under an assumed value of $D$, we separate the term $C_{2}$ of grain boundary diffusion calculated by eq. (1) from the observed value $\left(C_{\text {obs }}\right)$, and plot the logarithm of the term of lattice diffusion against $y^{2}$ as shown in Fig. 2, from the slope of which the value of $D$ can be obtained. This procedure is repeated until the assumed value of $D$ coincides with the calculated value of $D$. As shown in Fig. 2, a linear relationship is recognized between the logarithm of the volume diffusion term and $y^{2}$ for all of the specimens in the range up to $100 \mu \mathrm{m}$.

The values of $D, D^{\prime}$ and other parameters obtained through the analysis by the selfconsistent method are listed in Table 2, where

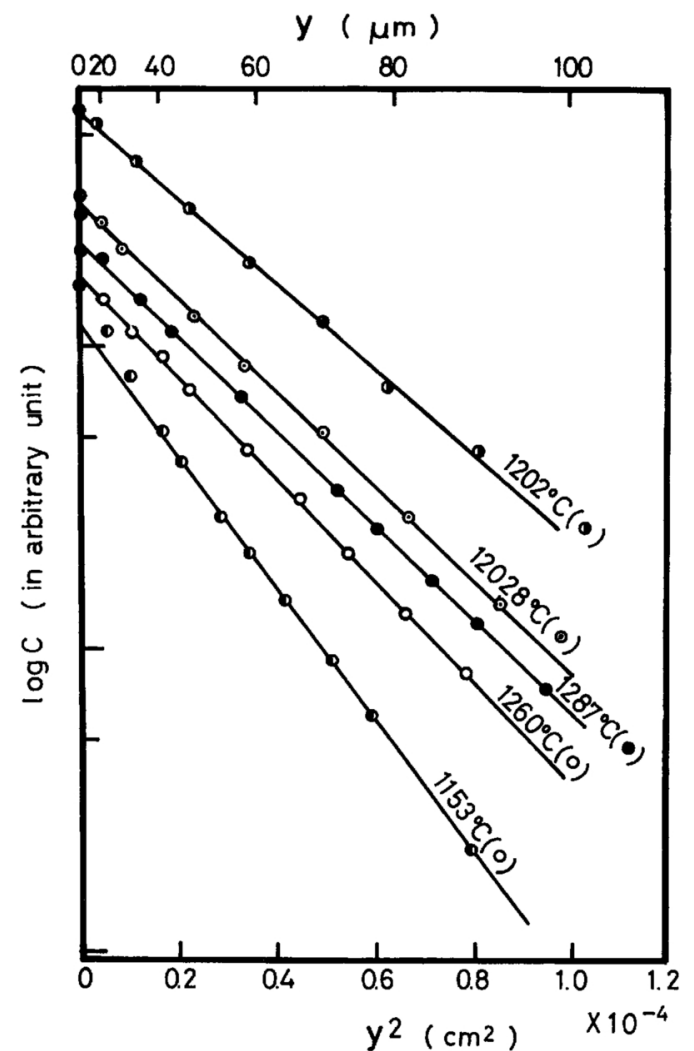

Fig. 2 Volume diffusion separated from grain boundary diffusion. 
Table 2 Grain boundary diffusion coefficient and other parameters of ${ }^{63} \mathrm{Ni}$ in to $\mathrm{Fe}$.

\begin{tabular}{lccccc}
\hline Specimen No. & 1 & 2 & 3 & 4 & 5 \\
\hline$T\left({ }^{\circ} \mathrm{C}\right)$ & 1287 & 1260 & 1228 & 1202 & 1153 \\
$1 / T \cdot 10^{4}\left(\mathrm{~K}^{-1}\right)$ & 6.4103 & 6.5232 & 6.6622 & 6.7797 & 7.0126 \\
$t \cdot 10^{-5}(\mathrm{~s})$ & 0.5964 & 0.9720 & 1.4598 & 2.3633 & 4.1712 \\
$\gamma \cdot 10^{-2}$ & 2.30 & 2.12 & 1.85 & 1.81 & 1.45 \\
$D \cdot 10^{15}\left(\mathrm{~m}^{2} \mathrm{~s}^{-1}\right)$ & 12.0 & 7.01 & 4.79 & 3.22 & 1.30 \\
$\sqrt{D \cdot t} \cdot 10^{5}(\mathrm{~m})$ & 2.68 & 2.61 & 2.64 & 2.76 & 2.33 \\
$\Delta \cdot 10^{5}$ & 2.53 & 2.98 & 3.70 & 3.67 & 6.36 \\
$D^{\prime} \cdot 10^{9}\left(\mathrm{~m}^{2} \mathrm{~s}^{-1}\right)$ & 3.03 & 2.09 & 1.77 & 1.18 & 0.83 \\
$\beta$ & 4.73 & 5.70 & 6.99 & 6.66 & 13.7 \\
$n$ & 11.6 & 11.4 & 12.4 & 17.9 & 16.1 \\
Effective grain & 0.62 & 0.60 & 0.66 & 0.99 & 0.75 \\
size (mm) & & & & \\
\hline \hline
\end{tabular}

$\beta=2 a(\Delta-1) / \sqrt{D \cdot t}$, and $2 a$ is the thickness of grain boundary, the value of which is $5 \times 10^{-8}$ $\mathrm{cm}$ according to Fisher.

The temperature dependence of lattice diffusion coefficients $(D)$ obtained in this experiment is represented by closed circles in Fig. 3, from which the present data are confirmed to be in good agreement with those of MacEvan et al. ${ }^{(10)}$ and Badia et al. ${ }^{(11)}$, and the least

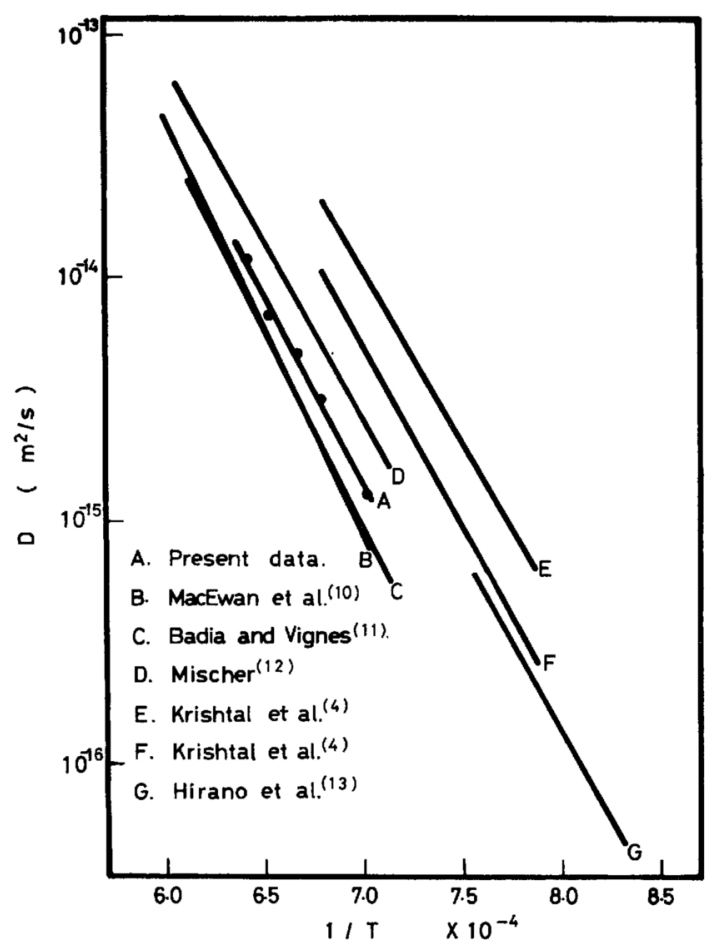

Fig. 3 Temperature dependence of volume diffusion coefficient $D$ of $\mathrm{Ni}$ in $\mathrm{Fe}$. squares calculation gives the relation

$$
\begin{aligned}
D= & 1.09 \times 10^{-4} \\
& \times \exp \left(-296.7 \mathrm{~kJ} \cdot \mathrm{mol}^{-1} / R T\right) \mathrm{m}^{2} / \mathrm{s} .
\end{aligned}
$$

Subsequently, the temperature dependence of grain boundary diffusion coefficient $\left(D^{\prime}\right)$ is represented by closed circles in Fig. 4, and the least squares calculation gives

$$
\begin{aligned}
D^{\prime}= & 24.1 \times 10^{-4} \\
& \times \exp \left(-176.2 \mathrm{~kJ} \cdot \mathrm{mol}^{-1} / R T\right) \mathrm{m}^{2} / \mathrm{s} .
\end{aligned}
$$

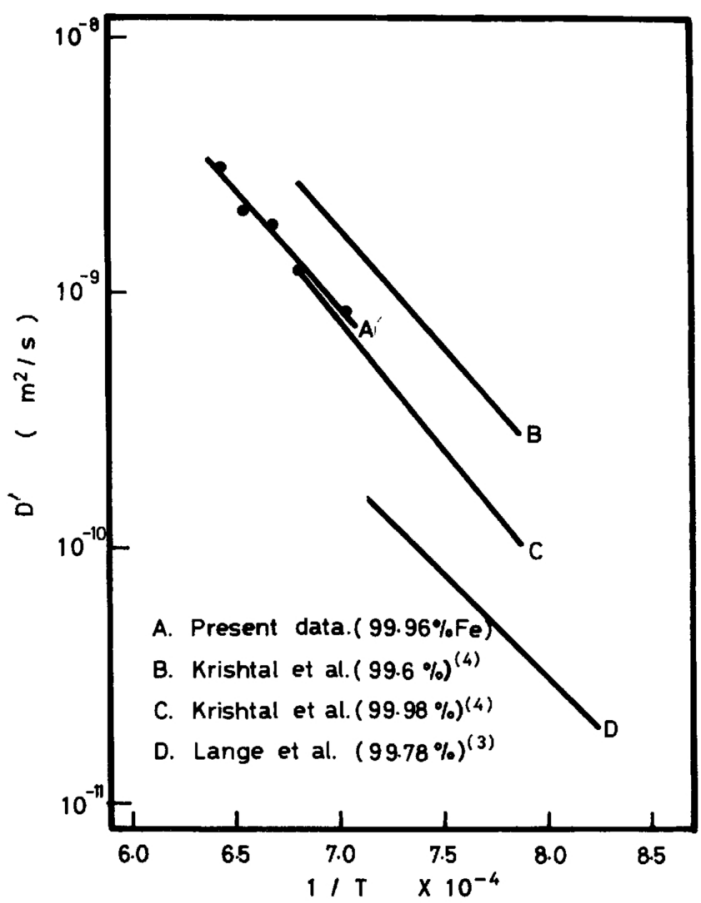

Fig. 4 Temperature dependence of grain boundary diffusion coefficient $D^{\prime}$ of $\mathrm{Ni}$ in $\mathrm{Fe}$. 
Table 3 Published data on diffusion of $\mathrm{Ni}$ in Fe.

\begin{tabular}{ccccl}
\hline & $\begin{array}{c}D_{0} \times 10^{4} \\
\left(\mathrm{~m}^{2} / \mathrm{s}\right)\end{array}$ & $\begin{array}{c}Q \\
(\mathrm{~kJ} / \mathrm{mol})\end{array}$ & $\begin{array}{c}\text { Temperature } \\
\text { range }\left({ }^{\circ} \mathrm{C}\right)\end{array}$ & \\
\hline $\mathrm{A}$ & 1.09 & 296.7 & $1153-1287$ & Present data \\
$\mathrm{B}$ & 6.92 & 324.7 & $1152-1400$ & MacEwan et al. \\
$\mathrm{C}$ & 3 & 313.8 & $1130-1360$ & Badia and Vignes \\
$\mathrm{D}$ & 0.44 & 278.7 & $1130-1380$ & Mischer \\
$\mathrm{E}$ & 0.9 & 270.7 & $1000-1200$ & Krishtal et al. \\
$\mathrm{F}$ & 1.25 & 283.3 & $1000-1200$ & Krishtal et al. \\
$\mathrm{G}$ & 0.77 & 280.3 & $930-1050$ & Hirano et al. \\
\hline
\end{tabular}

Table 4 Published data on grain boundary diffusion of $\mathrm{Ni}$ in $\mathrm{Fe}$.

\begin{tabular}{llccl}
\hline & $\begin{array}{c}D_{\mathbf{0}} \times 10^{4} \\
\left(\mathrm{~m}^{2} / \mathrm{s}\right)\end{array}$ & $\begin{array}{c}Q \\
(\mathrm{~kJ} / \mathrm{mol})\end{array}$ & $\begin{array}{c}\text { Temperature } \\
\text { range }\left({ }^{\circ} \mathrm{C}\right)\end{array}$ & \\
\hline $\mathrm{A}$ & 24.1 & 176.2 & $1153-1287$ & Present data \\
$\mathrm{B}$ & 40 & 173.6 & $1000-1200$ & Krishtal et al. \\
$\mathrm{C}$ & 50 & 185.8 & $1000-1200$ & Krishtal et al. \\
$\mathrm{D}$ & 0.77 & 152.3 & $940-1130$ & Lange et al. \\
\hline \hline
\end{tabular}

\section{Discussion}

Up to the present, the grain boundary diffusion coefficient has been obtained mainly by the theories based upon the constant source model $^{(5)(14)}$ in which the concentration of source at the surface of the specimen did not change during the diffusion annealing. In the impurity diffusion experiment, the layer composed of the diffusion source deposited upon the surface is usually extremely thin, so that the determination of the grain boundary diffusion coefficient at a high temperature using the above-mentioned constant source model is not valid. Therefore, the present data was analysed by the instantaneous souce model proposed by Suzuoka, in which the concentration of the surface source may vary with time during diffusion. Both of the frequency factor value of $1.09 \times 10^{-4} \mathrm{~m}^{2} / \mathrm{s}$ and the activation energy value of $296.7 \mathrm{~kJ} \cdot \mathrm{mol}^{-1}$ for the volume diffusion are in good accord with the literature values shown in Table 3 . On the other hand, there are only two reports about the boundary diffusion coefficients of $\mathrm{Ni}$ into $\mathrm{Fe}$, both of which are analysed by Fisher's method; one is the data reported by Langer et al. ${ }^{(3)}$ and the other is the data reported by Kristall et al. ${ }^{(4)}$ A large difference, however, is recognized be- tween them, and moreover Lange et al. used the extrapolated values of $D$ from those of Misher et al. ${ }^{(12)}$

The temperature dependence of the grain boundary diffusion coefficient obtained in this experiment is represented by a straight line as shown in Fig. 4, and the activation energy of $176.2 \mathrm{~kJ} \cdot \mathrm{mol}^{-1}$ calculated from the slope of it approximates the value of Kristall et al. more closely than that of Lange et al., as shown in Table 4. It is reported by James and Leak ${ }^{(15)}$ that the ratio of activation energy of the grain boundary diffusion coefficient to that of the lattice diffusion coefficient is 0.53 . Therefore the value $\left(Q^{\prime} / Q\right)$ of 0.59 obtained in this experiment is reasonable.

\section{Conclusion}

The temperature dependences of the volume diffusion coefficient and the grain boundary diffusion coefficient obtained in this experiment are given by

$$
\begin{aligned}
D= & 1.09 \times 10^{-4} \\
& \times \exp \left(-296.7 \mathrm{~kJ} \cdot \mathrm{mol}^{-1} / R T\right) \mathrm{m}^{2} / \mathrm{s}, \\
D^{\prime}= & 24.1 \times 10^{-4} \\
& \times \exp \left(-176.2 \mathrm{~kJ} \cdot \mathrm{mol}^{-1} / R T\right) \mathrm{m}^{2} / \mathrm{s} .
\end{aligned}
$$




\section{REFERENCES}

(1) For example, H. Mitani, Y. Hanatate and K. Majima: J. Japan Inst. Metals, 40 (1976), 903.

(2) Y. Hanatate, K. Majima and H. Mitani: J. Japan Inst. Metals, 40 (1976), 1010.

(3) W. Lange, A. Hässner und G. Mischer: Phys. Status Solidi, 5 (1964), 63.

(4) M. A. Krishtal, A. P. Mokrov, O. V. Stepanove and L. A. Concharenko: Zashch. Pokryt. Metal., 2 (1968), 209.

(5) J. C. Fisher: J. Appl. Phys., 22 (1951), 74.

(6) T. Suzuoka: Trans. JIM, 2 (1961), 25.

(7) R. E. Hoffman, E. W. Pikus and R. A. Ward:
Trans. Met. Soc. AIME, 206 (1956), 483.

(8) C. A. Mackliet: Phys. Rev., 109 (1958), 1964.

(9) T. Suzuoka: Trans. JIM, 2 (1961), 176.

(10) J. R. MacEwan, J. U. MacEwan and L. Yaffe: Can. J. Chem., 37 (1959), 1629.

(11) M. Badia and A. Vignes: Acta Met., 17 (1969), 177.

(12) G. Mischer: Diplomarbeit TU Dresden (1962).

(13) K. Hirano, M. Cohen and B. L· Averbach: Acta Met., 9 (1961), 440.

(14) R. T. P. Whipple: Phil. Mag., 45 (1954), 1225.

(15) D. W. James and G. M. Leak: Phil. Mag., 12 (1965), 491. 